\title{
Educação sexual na perspectiva dos temas transversais: uma revisão de literatura
}

Este artigo visa discorrer sobre a importância de trabalhar a educação sexual no meio escolar com a participação da família, no decorrer da exposição da pesquisa foram feitas conceituações a respeito da sexualidade, orientação sexual e identidade de gênero. No bojo deste trabalho contém, ainda, apresentação de informações que comprovam que uma a relação entre a efetivação da educação sexual na busca por diminuição dos índices de contágio de infecção e doenças sexualmente transmissíveis e gravidez não programadas, bem como a ocorrência de abuso sexuais. Para desenvolver a pesquisa foi utilizado o método bibliográfico que percorreu diversos trabalhos, obras, teses e outros artigos que tratam sobre a sexualidade dentro dos Temas Transversais propostos pelos Parâmetros Curriculares Nacionais. Objetiva-se que através deste trabalho seja reconhecida e reafirmada a importância da Educação Sexual nas Escolas com a participação da família e da sociedade, sempre em busca de proporcionar às crianças e adolescentes uma convicção apoiada sobre suas questões, opções e desafios sexuais.

Palavras-chave: Escola; Família; Sexualidade; Direitos Sexuais.

\section{Sex education from the perspective of transversal themes: a literature review}

This article aims to discuss the importance of working sex education in the school environment with the participation of the family, during the research exposition were made concepts about sexuality, sexual orientation and gender identity. At the heart of this paper, it also presents information that proves that the relationship between the implementation of sexual education in the search for a reduction in the infection rates of sexually transmitted diseases and unplanned pregnancies, as well as the occurrence of sexual abuse. To develop the research was used the bibliographic method that covered several works, works, theses and other articles that deal with sexuality within the Cross-cutting Themes proposed by the National Curriculum Parameters. The aim of this work is to recognize and reaffirm the importance of Sex Education in Schools with the participation of family and society, always seeking to provide children and adolescents with a conviction based on their sexual issues, options and challenges.

Keywords: School; Family; Sexuality; Sexual rights.

Topic: Ensinos Multidisciplinares

Reviewed anonymously in the process of blind peer
Received: 22/03/2019

Approved: 15/07/2019
Laisy Giordana Lopes Carvalho

Instituto Educacional Santa Catarina, Brasil http://lattes.cnpq.br/2733965769712173 laisygiordanal9@gmail.com

Marcela Coelho Jardim

Instituto Educacional Santa Catarina, Brasi http://lattes.cnpq.br/6774569323506809

marcela.coelho2015@hotmail.com

Ana Paula Martins Guimarães (iD

Universidade Federal do Tocantins, Brasil http://lattes.cnpq.br/5309168123830683 http://orcid.org/0000-0002-0926-7962

biologa.apmg@gmail.com

\section{Referencing this:}

CARVALHO, L. G. L.; JARDIM, M. C.; GUIMARÃES, A. P. M.. Educação sexual na perspectiva dos temas transversais: uma revisão de literatura. Educationis, v.7, n.2, p.19-29, 2019. DOI: http://doi.org/10.6008/CBPC2318-3047.2019.002.0003 


\section{INTRODUÇÃO}

Atualmente a sexualidade, em relação à formação da criança e do adolescente, tem se mostrado a cada geração como um parâmetro de precocidade, pois os jovens do século XXI tornam sua vida sexual ativa antes do amadurecimento psicológico, fisiológico, social e financeiro. Desta forma, compreende-se que se faz necessário a iniciativa de elaboração e execução de um plano de intervenção para a conscientização sobre as consequências advindas desse processo, assim como, orientação para a prática da sexualidade de forma consciente a fim de minimizar as sequelas que podem ser geradas devido à falta de informação quanto à uma relação sexual segura e o modo como a pratica.

Existe uma forte discordância entre a definição do sexo do indivíduo para a sua sexualidade, sendo que, esta afirmação parte do seguinte pressuposto: o gênero busca demonstrar as diferentes vias de determinação sexual que não estão intimamente ligadas à definição do viés heterossexual preconizado pela sociedade tradicional, sendo então que, a sexualidade não está vinculada a definição do gênero, mas sim as diferentes formas de atração sexual que serão diferenciadas a partir de uma orientação sexual eficaz.

Esta confusão quanto à indefinição sexual dos adolescentes pode levar a serias consequências na prática sexual indiscriminada, como por exemplo, as questões voltadas à aquisição de Infecções Sexualmente Transmissíveis (IST's). De acordo com estudos realizados por Szwarcwald et al. (2000), demonstrou que os indivíduos que fazem parte do público de adolescente do território brasileiro apresentam aspectos vulneráveis as IST's.

Segundo Gonçalves et al. (2009), a adolescência é período de descoberta, de dúvidas e conflitos internos, inclusive no campo sexual. Trabalhar sobre educação sexual na escola vai buscar evitar que tais indivíduos testem suas curiosidades sem saber dos riscos que decorrem tais práticas. Para Lins et al. (1988), as aventuras, por assim dizer, podem chegar a aquisição de doenças e infecções sexualmente transmissíveis, mas podem também promover uma gravidez não planejada, ambas opções devido à não proteção ou não utilização de métodos contraceptivos. A infecção ou doença, a depender do grau de periculosidade pode ser tratada e resolvida, todavia, uma criança, querendo ou não, interfere no futuro do adolescente, independente do sexo.

A educação sexual, como área do conhecimento, precisa iniciar na família, visto que é a base para a formação da identidade sexual da criança ou adolescente. Em razão dessa complexidade é que se faz tão necessário a abordagem deste tema. É notório que a mídia tem trazido à tona várias questões relacionadas à sexualidade, todavia, estar nos meios de comunicação não é garantia de que o assunto será abordado de forma correta e muito menos participativa (GONÇALVES et al., 2013).

E este artigo que é resultado de uma revisão de literatura em relação à educação sexual, aborda que a escola enfrenta um grande desafio hoje, que é formar cidadãos plenos e atuantes. Reconhece-se a dificuldade e a complexidade da tarefa, que exige das instituições um movimento que ultrapasse os temas, conteúdos e programas. Um dos assuntos mais difíceis de ser trabalhado dentro da educação sempre foi à sexualidade. 
A pesquisa que embasa este artigo, através de seu objetivo principal, busca evidenciar as áreas de contribuição da educação sexual seja ela na escola através da adequação dos temas transversais dentro da grade curricular ou na família por meio de diálogo e do exemplo pessoal. Além de mostrar como o respeito proporciona a vivência plena dos direitos sexuais que toda pessoa tem, inclusive crianças e adolescentes.

A realização do trabalho se justifica pela sua relevância social, pois se entende que é de suma importância trabalhar constantemente as questões sexuais com os adolescentes, considerando que, uma pessoa consciente pode escolher o caminho a seguir minimizando os riscos de aquisição de Infeç̧ões Sexualmente Transmissíveis, uma gestação indesejada, abusos sexuais e problemas de ordem psicossociais mediados por uma indecisão sexual ou por falta de conhecimento.

O presente trabalho objetiva, principalmente, realizar uma extensa revisão da literatura para a atualização do Tema Transversal 'Educação Sexual', voltado para as discussões para as seguintes temáticas: Definição de gênero e sexualidade; Gravidez Precoce; Infecções Sexualmente Transmissíveis; Participação familiar no processo de educação sexual do adolescente; Participação da Unidade Escolar no processo ensino-aprendizagem voltadas para a educação sexual.

\section{METODOLOGIA}

A pesquisa se deu pelo método bibliográfico, a qual se desenvolveu através de pesquisa física e virtual de livros, revistas, artigos, teses de mestrado e de doutorado que abordaram a educação sexual como sendo necessária para a formação social da criança e do adolescente (LAKATOS et al., 2003). De início foram realizados fichamentos dos textos encontrados, relacionando os objetivos, temas, e situação problema com o tema deste artigo. Para definir o que era compatível utilizou-se a comparação com o pré-projeto que norteou a elaboração desse artigo. Ao passo que se verificava a compatibilidade de ideias as obras iam sendo selecionadas para integrar o acervo de obras citadas e referenciadas no bojo deste trabalho. A pesquisa buscou ser o mais pertinente e direto possível para obter o melhor aproveitamento de tempo, recursos materiais e humanos, afim de resultar num material de boa qualidade que aborde os resultados encontrados e apresente coerentemente a análise e sua discussão.

\section{DISCUSSÃO TEÓRICA}

\section{Identidade de gênero, orientação sexual e sexualidade}

Dentro dos Temas Transversais destaca-se a Educação Sexual, apresentada como Educação Sexual e suas características físicas, anatômicas e biológicas, as relações afetivas e culturais determinadas pela sociedade. Segundo os Parâmetros Curriculares Nacionais (BRASIL, 1997), a sexualidade influencia diretamente no desenvolvimento psicológico, pois, não tem relação com a anatomia da pessoa, mas com o prazer (ALTMANN, 2001). Antes de entrar no mérito da identidade de gênero, orientação sexual e sexualidade é preciso conceituar esses termos, pois, apesar de parecerem sinônimos, possuem suas diferenças, seus conceitos se comunicam, mas não se confundem. 
Em relação à identidade de gênero Jesus (2012), assevera se tratar da expressão pessoal do indivíduo em definir e apresentar a si mesmo e à sociedade como homem ou mulher, ou seja, seu gênero pode até mesmo divergir da orientação dada no momento de seu nascimento, pois, ao nascer define-se a questão biológica que determina a pessoa como macho ou fêmea, onde questões ligadas aos cromossomos, reprodução, fatores hormonais e os órgãos genitais são, em regra, indiscutíveis, todavia, suas características, seu comportamento, forma e maneira de se expressar que forma sua identidade de gênero. Nesse sentido

As identidades são características fundamentais da experiência humana, pois, possibilita aos seres humanos a sua constituição como sujeitos no mundo social. $O$ gênero se refere à identidade com a qual uma pessoa se identifica ou se autodetermina; independe do sexo e está mais relacionado ao papel do indivíduo. Assim, essa identidade seria um fenômeno social.

Sobre a orientação sexual Jesus (2012), acrescenta a respeito em relação com à atração que cada indivíduo sente entre si. Essa atração é permeada de questões sentimentais, e não apenas sexuais. Nesse sentido, ao gostar de pessoas do sexo oposto, esse sujeito é heterossexual (ou heteroafetivo), no mesmo entendimento que se a atração for por alguém do mesmo sexo, a orientação será homossexual (ou homoafetiva), por fim, faz-se necessário citar aqueles que se interessam por ambos os sexos: os bissexuais (ou biafetivos).

Portanto, a orientação sexual, por sua vez, diz respeito à qual ou quais são as preferências sexuais da pessoa, por quem sente atração, podendo ser heterossexual que se atrai pelo gênero oposto ao que se identifica, homossexual que se atrai pelo mesmo gênero que se define, bissexual que se atrai por ambos os gêneros, ou não se atrai por ninguém que é a figura do assexual. Percebe-se que sexo biológico não influencia a preferência afetiva, pois, essa escolha se fundamenta no campo psicológico.

Para definir sexualidade é justo parafrasear Beauvoir, entende sexualidade como um conjunto de sentimentos inerentes, a qual se desperta ao nascer e é estabelecida no decorrer da vida, com todas as relações culturais e sociais que envolvem o indivíduo, bem como pelas relações afetivas de cada ser humano. Ao nascer, ninguém, está efetivamente preparado para estar num mundo e interagir com outras pessoas, essa consciência surge exatamente com o tempo de convivência com esses, até então, estranhos, é que a essência interior começa a sobressair e apresentar inclinações ao que the parece agradável e retenção ao que Ihe transpõe os seus limites pessoais.

A adolescência compreende a fase da vida em que o jovem passa por uma transição entre a infância e a fase adulta. Nesse período, o indivíduo sofre diversas mudanças anatômicas, fisiológicas, hormonais, psicológicas e sociais que acarretam na identidade como ser social. Assim também, como influencia diretamente na formação e estruturação de sua sexualidade.

Entretanto, segundo Figueiró (2001), há uma grande insegurança da comunidade escolar em trabalhar a Educação Sexual. Mesmo porque muitas das vezes não houve uma formação acadêmica com vistas a preparar o profissional nesse campo também, ou seja, há cursos de licenciatura que não propiciam uma segurança para abordar esse tema em sala de aula, além disso, há uma forte repressão da sociedade que, por ser muito tradicional ainda considera a sexualidade como algo promíscuo e imoral, e devido a isso tem receio de haver alienação sexual nas crianças, o que destoa totalmente do objetivo da Educação Sexual 
de orientar, esclarecer as dúvidas que surgem, garantir o conhecimento das diferenças e assim fomentar o respeito.

\section{A parceria da família e da escola pela educação sexual de qualidade}

Ao mencionar a necessidade de haver educação sexual nas escolas não se pode esquecer a relevância do papel da família. $\mathrm{O}$ afeto e a confiança na família deve ser algo natural e instintivo, por isso é benéfico utilizar essa proximidade em favor da boa formação desse em crescimento. Vale lembrar que apesar da família já ter seus preceitos e concepções sobre as questões sexuais não é louvável que elas sejam impostas, pelo contrário, elas devem ser expostas através do diálogo e seguidas somente se a criança ou adolescente achar conveniente e confortável para si, pois, trata-se de algo subjetivo, ou seja pessoal.

Todavia, há famílias que não conseguem discutir e trabalhar a educação sexual dentro de seus lares. Savegnago et al. (2013), acreditam que as barreiras argumentadas são a religião; o receio de banalizar o sexo; ou um bloqueio verbal, pois, às vezes a pessoa na condição de pai, mãe ou responsável quer tratar do assunto com a criança ou adolescente em sua responsabilidade e apesar de visualizar a necessidade não consegue iniciar o assunto e acaba deixando de lado esse encargo e, sem querer se tornando culpado (a) por uma possível consequência.

A família tem terceirizado a educação de seus filhos e atribuiu toda a responsabilidade de formação crítico e reflexiva à escola, porém essa não é a atitude adequada, o correto é haver a parceria da família com a escola para formar um indivíduo que esteja apto a se posicionar de maneira independente diante da sociedade, inclusive em relação à sua sexualidade e temas afins (GONÇALVES, 2009).

Nesse sentido dissertam Savegnago et al. (2013), que ao se deparar com dificuldades, muitos pais decidem se abster do importante papel que thes é devido sobre abordar questões que envolvam a sexualidade com seus filhos. Devido a isso outras instituições e não a familiar bem como outras pessoas, por vezes alheias à criação dessa pessoa em formação, acabam desempenhando o papel dos genitores. A escola, pelo dato de ser local de socialização de crianças e adolescentes, tem se mostrado uma ferramenta imprescindível para a educação sexual. Ao analisar a história da educação brasileira, numa amostra dos últimos trinta anos, é possível perceber que a grade curricular tem se tornado mais crítica e buscaram adequar as discussões sobre o papel da educação formal devido a acontecimentos ocorridos diversas situações na história.

Vale ressaltar que adolescência é, conforme Schoen-Ferreira et al. (2003), o período, a fase, mais difícil da vida de uma pessoa, ela passa por sérias alterações corporais e psicológicas, e uma ao mesmo tempo que a outra, é necessário tomar várias decisões, fazer escolhas e se recolher de outras que não são mais consideradas adequadas e/ou confortáveis para a idade. Tantas mudanças provocam confusões internas, se não houver quem dê o devido suporte as consequências são desastrosas.

É preciso fazer da educação sexual um fenômeno emancipador, que liberte na criança a sensação de ser livre e ser dono de seu corpo, que apenas ele pode tocar ou permitir que toquem, o que traduz a capacidade de se posicionar diante de situações de abuso sexual, por exemplo (VASCONCELOS, 1971). 
Vasconcelos (1971), afirma ainda que a educação sexual emancipatória tem várias funções e todas são extremamente importantes, dentre elas destaca-se: novas concepções sobre os aspectos fisiológicos com ênfase nas interpretações culturais, por fim, contribui para uma nova consciência e desenvolvimento de sua sensibilidade consigo mesmo.

Portanto, ao ministrar aulas sobre educação sexual faria com que as noções aprendidas em biologias deixassem de ser tão fechadas, abrindo a mentalidade paras as características psicológicas e morais, que em nada tem relação com a sexualidade naquilo que the pode dar significado e vivência autêntica: a procura mesmo da beleza interpessoal, a criação de um erotismo significativo do amor (CARVALHO et al., 2012).

Outro provável motivo para alguns pais não conseguirem conversar sobre sexualidade com seus filhos pode ser a existência de estigmas de suas próprias adolescências, em outras palavras, os pais sofreram repressão de seus pensamentos e sensações quando passavam pela mesma fase que seus filhos e conversar a respeito pode parecer reviver seus traumas causando angústia em alguns, assim segundo Levisky (1995), eles tendem a relacionar a sexualidade a algo vergonhoso.

Desse modo, para que haja uma orientação eficaz dos pais aos filhos é preciso que estes superem seus medos e seus bloqueios, se necessário buscando ajuda profissional, e em parceria, e não em segundo plano, com a escola estabeleçam ou reforcem a relação de confiança com os filhos que esses se sintam seguros em falar sobre sua sexualidade (GONÇALVES et al., 2009).

Costa (2007), acredita que a escola é o ambiente propício para mediar as questões da criança e as concepções da família. A autora afirma ainda que, a escola é um ambiente acolhedor onde pode propiciar à criança lidar com suas fantasias, frustrações, rejeição, depressão, agressões e agressividades, sem sentimento ambivalente de amor-ódio. Em relação ao desejo, a criança vai redimensionando suas ações e sentimentos, integrando na formação de sua personalidade aspectos adquiridos na relação com o outro (COSTA, 2007).

Suplicy (1983), acredita que a educação sexual nas escolas é resultado de um processo formal e sistemático que tem por objetivo promover a informação de forma a eliminar tabus e prevenir a sociedade contra preconceitos, além de promover debates sobre os obstáculos emocionais e valorativos que travam o estudo da sexualidade.

A criança e o adolescente, apesar de não ter capacidade plena que lhes confere deveres sociais, gozam de todos os direitos fundamentais da pessoa humana e tem outros privilégios estabelecidos pela legislação especial que os protegem o Estatuto da Criança e do Adolescente - ECA (1990). Mattos et al. (2008), diz a respeito da orientação sexual no espaço escolar que carece de focar não só no intuito de informar, pois, proporcionar uma transformação que mude a visão dos alunos também é válida. Se alunos visualizarem a sexualidade de forma positiva haverá bem menos incidência de fatos discriminatórios e prevalência de tabus.

Vale ressaltar que não adianta expor o aluno à uma chuva de informações e não o ajudar a refletir e absorvê-las. Cada um tem suas dúvidas e conflitos pessoais, essas informações também não podem ser direcionadas para não causar constrangimento, é necessário abordar todos os assuntos de forma que 
abranjam todas as possíveis necessidades. Se deixar disponível para uma busca pessoal e particular, se necessário.

\section{Educação sexual na prevenção das IST's e da Gravidez Precoce}

Não haver a discussão informativa sobre sexualidade tem forte relação com os dados de contração de Doenças Sexualmente Transmissíveis e gravidez precoce. A escola recua na intenção de trabalhar a Educação Sexual também pelo fato de que vários pais acreditam que os filhos aprenderão valores diferentes dos seus. Volta, então, a reforçar a necessidade da união da família com a escola para que haja a gestão participativa no objetivo de criar uma base didática que agrade a todos e atenda a necessidade dos alunos. É necessário acentuar a necessidade de um maior espaço para a educação sexual na grade curricular das escolas

A desinformação e a fragilidade da educação sexual são também questões problemáticas. As escolas e os sistemas de educação estão muito mais preocupados em dar conta das matérias cobradas em vestibular, como: física, química, português, matemática, etc., do que em discutir questões de cunho social.

Trabalhar a educação sexual pode parecer que incitará a prática sexual, todavia, essa teoria não se confirma, pois, ao contrário disso faz com que o início da vida sexual seja repensado, ou se iniciada que seja feita de forma consciente, evitando assim uma gravidez indesejada, por exemplo. Seguindo esse entendimento, Vianna (2012); elaborou uma produção acadêmica com foco inserção da definição de gênero e sexualidade na educação brasileira, essa pesquisa teve um recorte temporal da década da última década do século XX à primeira do século XXI.

Segundo Suplicy (1985), a vida sexual sem nenhuma base educativa colabora para a gravidez não programada em idade não apropriada para o corpo suportar uma gestação, muitos do sexo masculino enxergam o a atividade sexual como uma competição enquanto que do sexo feminino a tratam como maneira de promover sua liberdade, portanto, não há nenhuma vinculação o afeto, mas sim como uma ação resultante da repressão sexual que perdura desde primórdios da humanidade.

Lins et al. (1988), a educação sexual não visa apenas de colaborar com o planejamento sexual e familiar, mas, também para a prática sexual segura e consciente, colaborando, também, para a prevenção de Doenças Sexualmente Transmissíveis - DST's e Infecções Sexualmente Transmissíveis - IST's. Segundo o site da Câmara dos Deputados a medicina e educação têm apostado na educação sexual trabalhada interdisciplinarmente na escola para contribuir na prevenção de doenças sexualmente transmissíveis entre adolescentes (BRASIL, 2014).

Portanto, traduzir a linguagem médica do cientifico para o didático e inseri-la interdisciplinarmente nas escolas é capaz de diminuir os índices de gravidez e contágio de infecção ou doenças sexualmente transmissíveis na adolescência. Não é tirar o papel formador de profissionais que é incumbência da escola, mas agregar a função de formar um ser social também.

É missão da escola o ato de informar. Se omitir dessa responsabilidade em relação à sexualidade contribui para que os índices de pessoas com doenças sexualmente transmissíveis e também a quantidade 
de adolescentes grávidas continuem em alta (FIGUEIRÓ, 2004). Se todos foram, e de certa forma ainda são, vítimas durante milênios de preconceitos e tabus sexuais que se arrastam até a atualidade, é preciso evitar a transmissão dos próprios medos e sentimentos por vergonha diante dos filhos, alunos, crianças e adolescentes, em geral, que tem nos adultos exemplos.

Hoje as mídias televisivas e as redes sociais são os meios que estão sendo usados para propagar preconceito e desinformação, faz-se necessário utilizar tais ferramentas para beneficiar, para promover a boa informação e o respeito mútuo. Isso não é algo tão distante, pelo contrário, basta ter coragem e utilizar as informações que hoje batem à porta constantemente a favor do desenvolvimento sadio em todos os aspectos desse individuo em formação.

\section{Educação Sexual na Escola: Preconceitos e Tabus, um Desafio para a Gestão}

Para iniciar a discussão sobre a Educação Sexual na Escola é válido citar o que é proposto pelos Parâmetros Curriculares Nacionais (1997), em relação à sexualidade nas escolas, para só depois abordar sobre as estratégias de como fazê-lo. Como já dito, a sexualidade precisa ser introduzida na escola dentro da classificação de temas transversais, desse modo ela será aplicada de forma interdisciplinar, passando por cada disciplina na proporção que the couber.

Os PCNs (1997), propõem que na primeira e segunda fase do Ensino Fundamental a sexualidade, assim como os outros temas transversais, seja trabalhada dentro da programação onde o conteúdo educativo é organizado, planejado e seccionado entre os docentes, nada impede que seja feito em evento que trate exclusivamente do assunto, uma palestra ou oficina, por exemplo. Ou o assunto pode surgir de forma não programada dentro da sala de aula e o professor por se sentir preparado resolve ensinar, espontaneamente, o assunto aos seus alunos.

Figueiró (2001), afirma pensar que se os professores seguissem seriamente os novos Parâmetros não haverá dificuldade de trabalhar os temas transversais sem prejuízo da disciplina que leciona. Porque há viabilidade entres os conteúdos. Não é algo que precise de grandes elaborações ou ferramentas para agregar a sexualidade, por exemplo, pois a própria disciplina abre espaço.

É triste que alguns professores ao se deparar com situações que propiciariam o debate sobre sexualidade, tabus, e preconceitos se esquivam da sua responsabilidade e deixam de impor autoridade a fim de apaziguar os ânimos que, por vezes, se exaltam na sala de aula. Não se pode calar uma dúvida. Não é saudável nem humano. Mas, também não é correto imprimir sua opinião ou convicção pessoal sobre a questão que surge, professor não é formador de opinião o tempo todo, às vezes ele deve atuar de modo a desenvolver a opinião do próprio aluno. Figueiró (2001) afirma que:

É uma pena que as pessoas que participam do curso, em sua maioria, chegam com a intenção de aprender a 'cortar' a curiosidade dos alunos ou resolver de forma conservadora. Mas no decorrer do curso, percebem, conseguindo ver realmente como trabalhar com as crianças e adolescentes'.

Há a instrução de que ao ser questionado sobre questões sexuais o professor deve ater-se apenas ao que é perguntado. Porém, assim como assevera Campos et al. (2006), não somente responder ao que se 
pergunta é preciso conversar sobre o assunto, uma pergunta feita pode ser a 'ponta do iceberg' que demonstra uma imensidão de questões internas que uma criança ou adolescentes pode estar tendo sobre sexualidade.

\section{A sexualidade na prática de ensino de Biologia}

A sexualidade deve ser incluída nas diversas matérias previstas nas grades curriculares das escolas, porém se observa uma dominação desse contexto nas disciplinas de ciências e biologia, pois, já preveem questões a respeito da reprodução humana, por exemplo, mas, tudo no campo fisiológico. Debater sobre sexualidade é imprescindível para a edificação da identificação sexual do indivíduo que vai além da prática sexual ou das questões voltadas aos aspectos reprodutivos humanos, como também, aos vários aspectos afetos-sexuais praticados no decorrer da vivência individual de cada ser.

Para Barros et al. (2009), a ciência é uma disciplina privilegiada quanto ao estudo da sexualidade visto que esta já está vinculada à mesma, todavia, restringe à conhecimentos científicos que se prendem a estudar os sistemas reprodutores e a genitalidade, que são quesitos comuns a todos e relacionados apenas ao critério biológico sem levar em consideração a história e a cultura do indivíduo.

Mais uma contribuição para a conexão da sexualidade com as disciplinas de ciências e biologia é o conceito trazido pela modernidade do que vem a ser sexo, que determina os limites do que deve ser explicado em sala de aula e o que deve ser evitado, além de atribuir competência a quem tem função de discutir sobre sexualidade (ALTMANN, 2005; BONFIM, 2009).

Bianco (2017), afirma que reconhecer a sexualidade como tema transversal e atestar sua necessidade de ser inclusa no currículo escolar consiste em tratá-la como área de conhecimento a ser debatida dentro de outras áreas, aqui se incluem a biologia, matemática, psicologia, história, medicina, português e tantas outras, todavia, destaca-se a maior identificação do tema com as matérias de ciências e biologia, mas não há restrições quanto ao trabalho do mesmo em outras nem tampouco a instituição de profissional específico para fazê-lo.

Apesar da previsão pelos Parâmetros Curriculares Nacionais (1997), com caráter transversal, a educação focada na sexualidade tem sido desempenhada apenas por professores de Ciências e Biologia, não haveria nenhuma objeção quanto a isso se este ensino não abarcasse apenas os aspectos fisiológicos e médicos. Segundo Silva (2005), apresentar a sexualidade como um fato desconexo da história e da cultura tem contribuído para perpetuação do heterossexismo e, por consequência, da reprodução da homofobia e segregação de minorias relacionadas ao gênero.

Ao analisar os Parâmetros Curriculares Nacionais (1997), verifica-se uma omissão quanto às minorias sexuais e de gênero. $O$ que se constata são apenas menções que visam o respeito das diversidades inclusive no que diz respeito aos comportamentos atuais que têm conexão com a sexualidade, desde que seja garantida a dignidade do ser humano. Destaca-se ainda alusões que tendem ao reconhecimento de determinações culturais os aspectos relacionados ao que é masculino ou feminino e posicionando contra toda e qualquer preconceito a respeito (BRASIL, 1997). 
Vale ressalta que o questionamento da relevância da escola no que que se refere 'transmissão dos conhecimentos sistematizados, historicamente pela humanidade' pôs em cheque a soberania da ciência comum e agregou os conhecimentos originados dos movimentos sociais na grade curricular efetivando, assim, a multiplicidade. Embora ainda seja complexo um ensino de Biologia capaz de entender as necessidades de todos os adolescentes de hoje, com relação a Educação Sexual, o trabalho com essa temática ainda pode acrescentar uma grande diversidade de ações heterogêneas, acrescentando pontos de vista psicológicos e até mesmo sociais.

\section{CONCLUSÕES}

Essa pesquisa se pautou na busca pela justificativa e amparo para a introdução da educação sexual na educação de crianças e adolescentes. Ao longo da elaboração do artigo foi se percebendo que a importância do debate do tema na atualidade. Não é uma obrigação apenas didática, é uma questão social. Ao final, constata-se que apesar de ser uma necessidade visível e notória tanto para as famílias quanto para a escola, sociedade e até mesmo o Governo Federal não tem se empenhado para promover a educação sexual. O Governo como entidade estatal precisa garantir a formação continuada dos professores no intuito de neutralizar as concepções destes no momento de transmissão dos ensinamentos desse tema.

Os pais precisam se portar como componentes úteis e imprescindíveis para educação de seus filhos o que inclui a educação sexual. Aprender a comparecer mais à escola e, em casa, exercer seu papel como base da educação que as crianças e adolescentes irão desenvolver no âmbito escolar. Quando todos estiverem unidos em prol do desenvolvimento educacional, social e sexual das crianças e adolescentes as questões e dúvidas dessa fase serão mais fáceis de transpor, os índices negativos serão reduzidos e haverá mais respeito e compreensão às diferenças.

\section{REFERÊNCIAS}

ALTMANN, H.. Verdades e pedagogias na educação sexual em uma escola. Tese (Doutorado) - Pontifícia Universidade Católica, Rio de Janeiro, 2005.

BARROS, S. C.; QUADRADO, R. P.; RIBEIRO, P. R. C.. Sexualidade no Currículo Escolar: Disciplinaridade ou Transversalidade?. In: ENCONTRO NACIONAL DE PESQUISA EM EDUCAÇÃO EM CIÊNCIAS. Anais. Florianópolis, 2009.

BIANCO, A. P.. Tema Transversal Orientação Sexual, Prática pedagógica do Professor de Educação Física: Trajetórias e Desafios. Araraquara: UNESP, 2017.

BONFIM, C. R. S.. Educação sexual e formação de professores de ciências biológicas. Tese (Doutorado em Educação) - Universidade Estadual de Campinas, Campinas, 2009.

BRASIL. Secretaria de Educação Fundamental. Parâmetros Curriculares Nacionais: Pluralidade Cultural, orientação sexual. Brasília: SEF, 1997.

BRASIL. Lei n. 8069, 13/07/1990. Estatuto da Criança e do Adolescente. Brasília: DOU, 1990.
BRASIL. Secretaria de Educação Fundamental. Parâmetros Curriculares Nacionais: Pluralidade Cultural e Orientação Sexual. Temas Transversais. Rio de Janeiro: DP\&A, 2000.

BRASIL. Médicos e educadores defendem educação sexual para evitar doenças. Brasília: Câmara Notícias, 2014.

CAMPOS, R. V.; BARBOSA, S. A.. A Sexualidade e a sala de aula. Transversal, v.4, n.4, 2006.

CARVALHO, F. A.; BERTOLLI FILHO, C.. Sexualidade e Educação Sexual: Enunciações e Dispositivos nos contextos de ensino de Ciências. São Paulo: Universidade Estado de São Paulo, 2012

COSTA, A. C.. Psicopedagogia e psicomotricidade: pontos de intersecção nas dificuldades de aprendizagem. 5 Ed. Petrópolis: Vozes, 2007.

FIGUEIRÓ, M. N. D.. A formação de educadores sexuais: possibilidades e limites. Tese (Doutorado em Educação) Universidade Estado de São Paulo, Marilia, 2001. 
FIGUEIRÓ, M. N. D.. Educação Sexual: Como Ensinar no Espaço Escolar. São Paulo: Universidade do Estado de São Paulo, 2004.

GONÇALVES, B.. Adolescência é período da descoberta de si mesmo, diz psicólogo. São Paulo: Rudge Ramos, 2009.

GONÇALVES, R. C.; FALEIRO, F. H.; MALAFAIA, G.. Educação Sexual no contexto escolar: impasses e desafios. Honos, v.29, n.5, 2013

JESUS, J. G.. Orientações sobre identidade de gênero: conceitos e termos. Brasília, 2012.

LAKATOS, E. M.; MARCONI, M. A.. Fundamentos da metodologia científica. 5 ed. São Paulo: Atlas, 2003.

LEVISKY, D. L.. Adolescência: reflexões psicanalíticas. Porto Alegre: Artes Médicas, 1995.

LINS, L. C. S.; PEREIRA, E. M. D. R.; LIRA, I. V.. Como anda a Educação Sexual dos Jovens. R. Bras. Enferm., Brasília, v.41, n.2, p.123-131, 1988.

MATTOS, A. H.; FERREIRA, A.; JABUR, S. S.. O papel do educador na construção de uma sexualidade emancipadora no Colégio Estadual Gabriel de Lara em Matinhos-PR. Matinhos, 2008.

SAVEGNADO, S. D. O.; ARPINI, D. M.. Escola, Família e Sexualidade: Diálogos Possíveis?. Brasília: UNB, 2013.
SCHOEN-FERREIRA, T. H.; AZNAR-FARIAS, M.; SILVARES, E. F. M.. A construção da identidade em adolescentes: um estudo exploratório. Estudos de Psicologia, 2003.

SILVA, E. P. Q.. Quando o corpo é uma (des)construção cultural. In: MARANDINO, M.; SELLES, S. E.; FERREIRA, M. S.; AMORIM, A. C.. Ensino de biologia: conhecimentos e valores em disputa. Niterói: Eduff, 2005.

SUPLICY, M.. Conversando sobre seu sexo. 12 ed. Petrópolis: Vozes, 1985.

SUPLICY, M.. Conversando sobre sexo. São Paulo: Vozes, 1983.

SZWARCWALD, C. L.; CASTILHO, E. A.; BARBOSA JR, A.; GOMES, M. R. O.; COSTA, E. A. M. M.; MALETTA, B. V.; CARVALHO, R. F, M.; OLIVEIRA, S. R.; CHEQUER, P.. Comportamento de risco dos conscritos do Exército Brasileiro, 1998: uma apreciação da infecção pelo HIV segundo diferenciais socioeconômicos. Cadernos de Saúde Pública, Rio de Janeiro, v.1, n.16, 2000.

VASCONCELOS, N.. Os dogmatismos sexuais. Rio de Janeiro: Paz e Terra, 1971.

VIANNA, C.; UNBEHAUM, S.. Gênero na Educação Básica: quem se importa?. Uma análise de documentos de Políticas Públicas no Brasil. Educação \& Sociedade, Campinas, v.27, n.95, 2006.

A CBPC - Companhia Brasileira de Produção Científica (CNPJ: 11.221.422/0001-03) detém os direitos materiais desta publicação. Os direitos referem-se à publicação do trabalho em qualquer parte do mundo, incluindo os direitos às renovaç̃ões, expansões e disseminações da contribuiç̃o, bem como outros direitos subsidiários. Todos os trabalhos publicados eletronicamente poderão posteriormente ser publicados em coletâneas impressas sob coordenação da Sustenere Publishing, da Companhia Brasileira de Produção Científica e seus parceiros autorizados. Os (as) autores (as) preservam os direitos autorais, mas não têm permissão para a publicação da contribuição em outro meio, impresso ou digital, em português ou em tradução. 